\title{
VITAL VALUES AND PHYSICAL ACTIVITY OF FUTURE TEACHERS
}

original paper

( ) University School of Physical Education in Wroclaw

DOI: https://doi.org/10.5114/hm.2019.77836

\section{GRAZYNA KOSIBA ${ }^{1}$, AGNIESZKA BOGACZ-WALANCIK ${ }^{2}$, MARIA GACEK ${ }^{3}$, AGNIESZKA WOJTOWICZ ${ }^{4}$, MAGDALENA MAJER ${ }^{1}$}

${ }^{1}$ Department of Theory and Methodology of Physical Education, Faculty of Physical Education and Sport,

University of Physical Education in Krakow, Krakow, Poland

${ }^{2}$ Sport and Recreation Center, Pedagogical University of Cracow, Krakow, Poland

${ }^{3}$ Department of Sports Medicine and Human Nutrition, Faculty of Physical Education and Sport,

University of Physical Education in Krakow, Krakow, Poland

${ }^{4}$ Department of Psychology, Faculty of Physical Education and Sport, University of Physical Education in Krakow,

Krakow, Poland

\section{ABSTRACT}

Purpose. The key determinant of health, defined in the holistic model as a dynamic process aiming at psycho-physiological balance, is lifestyle. Values, as an integrated part of people's beliefs, exert a significant influence on their behaviour, choices, development of identity, and interpretation of situations. The purpose of this study was to determine the place of vital values within the system of values, and to analyse the relationship between the place of vital values and the level of physical activity in future teachers.

Methods. The study was conducted among a randomly selected group of 486 students, including 416 women (85.60\%) and 70 men (14.40\%) (mean age: 23.39 years). A short version of the International Physical Activity Questionnaire (IPAQ) was used to assess the level of physical activity. The Scheler Value Scale (SVS) served to evaluate the place of vital values in the students' hierarchy of values.

Results. It was found that students respected moral and truth values the most, while vital values the least. The respondents were most likely to undertake moderate physical activity, with more men than women declaring a high level of physical activity and less often a moderate level. The more the students respected vital values, the more often they undertook physical activity. Conclusions. The results have shown that more attention should be given to axiological education in order to enhance vital values in the hierarchy of values among future teachers.

Key words: future teachers, hierarchy of values, vital values, physical activity, health education

\section{Introduction}

The key determinant of health, defined in the holistic model as a dynamic process aiming at a psycho-physiological balance, is lifestyle. In the context of health promotion, lifestyle is defined as collective patterns of healthrelated behaviours based on choices from options available to people according to their life chances, but also as values and attitudes held by people in response to their social, cultural, and economic environment [1].
The term 'health' can represent multiple areas of meaning. It is most often referred to as a value, a set of health determinants, a result of its status measurement, or as a set of health criteria. The perception of health as a value allows us to analyse it from the perspective of not only medicine and biology, but also such sciences as psychology, sociology, philosophy, which are becoming increasingly more important in pedagogical discourse. A multifaceted definition of health corresponds to its holistic concept (represented

Correspondence address: Grażyna Kosiba, Department of Theory and Methodology of Physical Education, Faculty of Physical Education and Sport, University of Physical Education in Krakow, al. Jana Pawła II 78, 31-571 Krakow, Poland, e-mail: kosiba@bema.krakow.pl

Received: March 28, 2018

Accepted for publication: August 5, 2018

Citation: Kosiba G, Bogacz-Walancik A, Gacek M, Wojtowicz A, Majer M. Vital values and physical activity of future teachers. Hum Mov. 2019;20(1):75-82; doi: https://doi.org/10.5114/hm.2019.77836. 
G. Kosiba, A. Bogacz-Walancik, M. Gacek, A. Wojtowicz, M. Majer, Students' values and physical activity

by the World Health Organization), whereby a person aware of their needs becomes a significant creator of health.

Values, as an integrated part of people's beliefs, exert a significant influence on their behaviour, choices, development of identity, as well as the interpretation of situations. With the assumption that values determine human behaviour, the place of health in the system of values may be responsible for the pursuit of health-promoting actions. Health is not only an expected and declared value, but also an inherent aspect of human development. Among a variety of values attributed to the human body, such as the aesthetic, hedonistic, and utilitarian ones, these are vital values, including health, physical fitness, and well-being, that underlie active pursuit of primary goals bound with maintaining, protecting, and developing one's psychophysical potential.

Among factors determining a healthy lifestyle, such as a rational diet, recreational physical activity, coping with psychological stress, avoiding psychoactive substances and risky sexual behaviour, as well as undergoing routine check-ups, systematic physical activity is a key factor affecting the health of an individual. Physical activity can be viewed as a factor which genetically modifies programmed health potential, improves overall physiology, affects particular health behaviours, and enhances emotional state [2]. In social sciences, physical activity is considered to foster integration and limit social isolation. In addition, as a reason for activation in other areas of a person's life, it enhances self-esteem and self-evaluation, while improving the quality of life [3].

Health awareness, which is shaped through acquiring knowledge about health and developing pro-health attitudes and skills, is directly linked to the process of socialization. The value of health is internalized via the implementation of complex educational programmes and the development of conditions promoting the value as well as proper pro-health behaviours. Influencing health awareness in the society is one of the basic tasks of education, and the importance of health care should be identified with health not only as an existential, biological, and social value, but also as an element included in the system of human values. Furthermore, it should be a primary educational duty of schools and teachers. The fact that health education of children and adolescents has been recognized and incorporated into the educational systems of all European countries should be underlined $[4,5]$. For example, in Poland, the role of a teacher as a health educator has been highlighted in key educational and training documents: the core curricula [6] and the standards of teacher education [7]. Biomedical and psychosocial issues related to health and health education as a holistic construct have also been included in teacher education standards. Currently, higher education institutions offering teacher education courses are required to provide students with content in this field. Also in Germany, the basic goals and tasks of schools in each federal state involve health education. Its primary aim is to provide children and adolescents with a healthy upbringing. For example, in Bavaria, it was assumed that young people should learn not only to act independently and responsibly, treat people of all origins with respect and without prejudice, learn the values of different cultures, understand the basic norms of the constitution, and fight for the values of democracy, but also to adhere to existence with movement and the common practice of sport, nourish health, and pursue a healthy lifestyle [8]. In Spain, for instance, the objectives and tasks of general education which involve shaping attitudes and habits that promote health, wellbeing, proper nutrition, and physical activity, have been defined in the decrees of the autonomous communities [9].

The formal acknowledgment of health values by authorities influencing the education of children and young people is essential for the development of school health education, public awareness, and healthy behaviours. Hence, it is imperative to make teaching staff conscious of health issues in education at the university level [10]. Proper preparation of students - future teachers - in the area of pro-health competences, knowledge, and skills, is a prerequisite for an effective implementation of health education and promotion into schools and local environments.

It is assumed that values drive human behaviours; therefore, the allocation of health in the hierarchy of values may affect health-promoting behaviours. Thus, knowing the place of vital values (including health) within the system of values held by future teachers may help determine whether they will be likely to engage in health education of schoolchildren as full-time teachers.

The purpose of the study was to identify the place of vital values in the hierarchy of values held by teaching specialization students, as well as to analyse the relationship between the place of vital values and the level of physical activity undertaken by the students. The following hypothesis was verified: the students future teachers - who find the vital values significant declare higher levels of physical activity than the individuals with less respect to vital values. 


\section{Material and methods}

\section{Participants}

The study was conducted in years 2013-2014 among a randomly selected group of 486 students, including 416 women $(85.60 \%)$ and 70 men $(14.40 \%)$, aged $22-$ 28 years (mean age: 23 years). The research involved third-year BA teaching specialization students at three different universities in Poland. The discrepancies in the number of males and females resulted from the general unpopularity of the teaching profession among men.

\section{Procedure}

A short version of the International Physical Activity Questionnaire (IPAQ) was used to assess the level of physical activity. The categories under investigation were: sitting, walking, as well as moderate and vigorous physical activity. On the basis of the measurement of metabolic equivalents of the task (MET), the subjects were classified into groups according to their level of physical activity: (a) high (one of the two criteria: $\geq 3$ days of vigorous physical effort, a minimum of 1500 MET-min/week, or $\geq 7$ days of any combination of efforts exceeding 3000 MET-min/week); (b) moderate (one of the three criteria: $\geq 3$ days of vigorous physical activity, not less than 20 minutes a day, or $\geq 5$ days of moderate effort or walking for a minimum of $30 \mathrm{~min}$ utes per day, or $\geq 5$ days of any combination of physical activity exceeding 600 MET-min/week); (c) low (failure to meet the criteria of moderate and high level of physical activity) [11].

The Scheler Value Scale (SVS) was used to evaluate the place of vital values in the students' hierarchy of values. The validity of 50 different values included on 6 basic scales was measured. The scales comprised the following values: hedonistic, vital, aesthetic, truth, moral, and sacred. On the basis of factor analysis, 2 subscales of vital values, i.e. fitness and physical condition, and resistance to fatigue, were additionally evaluated, as well as 2 subscales of sacred values, i.e. patriotic and religious values [12].

\section{Data analysis}

Statistical analysis was performed with the declared hierarchy of values and the level of physical activity between males and females, and the correlation between the variables was determined.

The analyses were carried out with the Statistica 13 software. The Student's $t$-test (in the absence of group homogeneity, the $t$-test was used with a separate estimation of variance), chi-squared analysis with multiple comparisons (correlation tests with Bonferroni correction, percentages in letters a and b), and Pearson's correlation analysis were applied. The normality of the distribution of quantitative variables was determined by the Shapiro-Wilk test and the histogram analysis. Not all respondents completed all questionnaires; therefore, the analyses may vary in terms of the number of subjects. The level of statistical significance was assumed as $\alpha=0.05$.

\section{Ethical approval}

The research related to human use has been complied with all the relevant national regulations and institutional policies, has followed the tenets of the Declaration of Helsinki, and has been approved by the authors' institutional review board or an equivalent committee.

\section{Informed consent}

Informed consent has been obtained from all individuals included in this study.

\section{Results}

Position of vital values in the students' hierarchy of values

The analysis of value hierarchy has shown that male and female students rate moral values (i.e., benevolence, frankness, and honour) the highest, followed by values of truth (i.e., intelligence, wisdom, and openmindedness). Subsequently, the female students indicated sacred religious values, such as God, faith, and salvation, whereas the male students pointed to hedonistic values, including erotic love and affluence. Vital values, i.e. gender-free life values, were indicated as $8^{\text {th }}$, prior to resistance to tiredness and aesthetic values. Fitness and physical condition were ranked as seventh in women, and fifth in men. Resistance to fatigue and the ability to quench cold and hunger were marked as second to last in the female students, and as the last by the male students (Table 1). Aesthetic values, including elegance, taste, regularity of features, and order of things, were ranked as the least important. A statistically significant difference between the female and male students was found with regard to values regarding truth, which was more appreciated by men, while sacred religious values were more respected by women. The data in Table 1 also show that men had a higher average score concerning the vital value of fitness and 


\section{HUMAN MOVEMENT}

G. Kosiba, A. Bogacz-Walancik, M. Gacek, A. Wojtowicz, M. Majer, Students' values and physical activity

physical condition than women, but the difference was not statistically significant.

Physical activity of teaching

specialization students

The data obtained from IPAQ showed that more than a half of the participants (62.14\%) frequently engaged in physical activity at a moderate level. While a smaller group of students (26.54\%) indicated a higher than average level of physical activity, almost $12 \%$ of all students did not meet the criteria for moderate and high levels of physical activity (Table 2). The statistical analysis revealed significant differences in the level of physical activity undertaken by women and men $\left(c^{2}{ }_{(2)}=6.521 ; p=0.038\right)$. The men declared a high level of physical activity more often than the women and a moderate level less often. It was also found that more male than female students indicated a low level of physical activity, but the differences were not statistically significant (Table 2).

As far as the four categories of physical activity included in the IPAQ questionnaire are concerned (Table 3), the highest values were obtained for walking and vigorous physical activities, and the lowest values for moderate exercise and sitting. In addition, men scored higher than women on vigorous and moderate activities and walking, and lower on sitting, but the differences did not reach the level of statistical significance.

Table 1. Descriptive statistics of the Scheler Value Scale items in teaching specialization students according to gender

\begin{tabular}{|c|c|c|c|c|c|c|c|c|}
\hline \multirow{2}{*}{ Values } & \multicolumn{2}{|c|}{ Total } & \multicolumn{2}{|c|}{ Women } & \multicolumn{2}{|c|}{ Men } & \multirow{2}{*}{$t$} & \multirow{2}{*}{$p$} \\
\hline & $M$ & $\underline{S D}$ & M & $S D$ & M & $S D$ & & \\
\hline Moral & 81.41 & 11.77 & 81.63 & 11.73 & 80.12 & 12.00 & 1.00 & 0.320 \\
\hline Truth & 76.21 & 13.19 & 75.37 & 13.13 & 81.21 & 12.48 & -3.47 & 0.001 \\
\hline Sacred religious & 74.26 & 29.09 & 75.52 & 28.20 & 66.75 & 33.13 & 2.35 & 0.019 \\
\hline Hedonistic & 68.73 & 14.94 & 68.69 & 14.93 & 68.92 & 15.11 & -0.12 & 0.905 \\
\hline Sacred & 66.28 & 20.70 & 66.28 & 20.25 & 66.25 & 23.34 & 0.01 & 0.991 \\
\hline Sacred patriotic & 60.96 & 23.88 & 60.12 & 23.25 & 65.92 & 27.01 & -1.89 & 0.060 \\
\hline Fitness and physical condition & 57.58 & 21.66 & 56.88 & 21.60 & 61.74 & 21.75 & -1.74 & 0.082 \\
\hline Vital & 55.15 & 19.95 & 54.90 & 19.63 & 56.67 & 21.84 & -0.69 & 0.492 \\
\hline Resistance to tiredness & 52.73 & 23.58 & 52.92 & 23.04 & 51.60 & 26.70 & 0.43 & 0.666 \\
\hline Aesthetic & 51.37 & 18.81 & 50.90 & 18.67 & 54.18 & 19.53 & -1.35 & 0.176 \\
\hline
\end{tabular}

$M$ - mean, $S D$ - standard deviation, $t$ - Student's $t$-test, $p$ - $p$-value

Table 2. Level of physical activity in teaching specialization students according to gender

\begin{tabular}{|c|c|c|c|c|c|c|}
\hline \multirow{2}{*}{ Level of physical activity } & \multicolumn{2}{|c|}{ Total } & \multicolumn{2}{|c|}{ Women } & \multicolumn{2}{|c|}{ Men } \\
\hline & $n$ & $\%$ & $n$ & $\%$ & $n$ & $\%$ \\
\hline High & 129 & 26.50 & $103^{b}$ & 24.80 & $26^{\mathrm{a}}$ & 37.10 \\
\hline Moderate & 302 & 62.10 & $268^{\mathrm{b}}$ & 64.40 & $34^{\mathrm{a}}$ & 48.60 \\
\hline Low & 55 & 11.30 & $45^{\mathrm{a}}$ & 10.80 & $10^{\mathrm{a}}$ & 14.30 \\
\hline Total & 485 & 100.00 & 416 & 100.00 & 70 & 100.00 \\
\hline
\end{tabular}

${ }^{\mathrm{a}, \mathrm{b}}$ proportion tests with Bonferroni correction (significantly different values)

Table 3. Physical activity categories in teaching specialization students by gender (MET-min/week)

\begin{tabular}{|c|c|c|c|c|c|c|c|c|c|c|c|}
\hline \multirow{2}{*}{ IPAQ categories } & \multicolumn{3}{|c|}{ Total } & \multicolumn{3}{|c|}{ Women } & \multicolumn{3}{|c|}{ Men } & \multirow{2}{*}{$t$} & \multirow{2}{*}{$p$} \\
\hline & $n$ & $M$ & $S D$ & $n$ & $M$ & $S D$ & $n$ & $M$ & $S D$ & & \\
\hline IPAQ vigor & 468 & 1194.27 & 2042.66 & 400 & 1120.40 & 1750.19 & 68 & 1628.82 & 3258.33 & -1.26 & 0.213 \\
\hline IPAQ moderate & 461 & 719.91 & 1366.19 & 393 & 650.43 & 1126.42 & 68 & 1121.47 & 2280.14 & -1.67 & 0.099 \\
\hline IPAQ walking & 445 & 2859.21 & 2861.35 & 385 & 2816.19 & 2842.92 & 60 & 3135.27 & 2986.81 & -0.80 & 0.422 \\
\hline IPAQ sitting & 393 & 399.24 & 169.42 & 340 & 402.79 & 170.03 & 53 & 376.42 & 165.22 & 1.05 & 0.292 \\
\hline IPAQ general & 418 & 4819.85 & 4497.27 & 362 & 4595.66 & 4053.36 & 56 & 6269.06 & 6560.31 & -1.85 & 0.068 \\
\hline
\end{tabular}

$M$ - mean, $S D$ - standard deviation, $t$ - Student's $t$-test, $p$ - $p$-value 
Table 4. Correlation between vital values, fitness and physical condition, and resistance and the intensity of individual IPAQ categories as well as the general index of physical activity among participants

\begin{tabular}{lccccc}
\hline \multirow{2}{*}{ Values } & \multicolumn{4}{c}{ Pearson's $r$} \\
\cline { 2 - 6 } & IPAQ general & IPAQ vigorous & IPAQ moderate & IPAQ walking & IPAQ sitting \\
\hline \multirow{2}{*}{ Vital } & $\begin{array}{l}0.19^{* * *} \\
n=418\end{array}$ & $\begin{array}{c}0.17^{* * *} \\
n=468\end{array}$ & $\begin{array}{c}0.16^{* *} \\
n=461\end{array}$ & $\begin{array}{c}0.10^{*} \\
n=445\end{array}$ & $\begin{array}{c}-0.08 \\
n=393\end{array}$ \\
\hline \multirow{2}{*}{ Fitness and physical condition } & $0.20^{* * *}$ & $0.20^{* * *}$ & $0.20^{* * *}$ & 0.08 & $-0.12^{*}$ \\
& $n=418$ & $n=468$ & $n=461$ & $n=445$ & $n=393$ \\
\hline \multirow{2}{*}{ Resistance } & $0.14^{* *}$ & $0.10^{*}$ & 0.09 & 0.09 & -0.02 \\
& $n=418$ & $n=468$ & $n=461$ & $n=445$ & $n=393$ \\
\hline
\end{tabular}

${ }^{*} p<0.05,{ }^{* *} p<0.01,{ }^{* * *} p<0.001$

Vital values and physical activity relationship

Correlational analysis revealed a statistically significant positive correlation between vital values and two subscales, i.e. fitness and physical condition, as well as resistance to fatigue, and the general physical activity index. The more the students respected vital values, including fitness and physical condition, and resistance, the higher level of physical activity they showed (Table 4). The strongest relationship was found between the level of physical activity, fitness and physical condition values, while the weakest one was between the level of physical activity and resistance values. In addition, a relationship of vital values and their two subscales - fitness and physical condition, and resistance - with IPAQ vigorous activity was detected. Significant positive correlations were also identified between vital values and the subscales of fitness and physical condition, and moderate activity (IPAQ moderate), and also between vital values and walking activity (IPAQ walking). Conversely, negative correlations were observed between vital values and fitness and physical condition subscales, and the sitting activity (IPAQ sitting).

\section{Discussion}

The analysis of the hierarchy of values among future teachers has shown that they find moral and truth values the most important. Subsequently, sacred religious values were indicated as the third most respected, followed by hedonistic values. Vital values, as compared with other ones included in the SVS, were rated as low by the students ( $8^{\text {th }}$ place out of 10 possible). In addition, it was observed that the values of fitness and physical condition, including aspects such as physical condition, agility, endurance, which involves resistance to fatigue and the ability to quench cold and hunger, were also of little value to the students $\left(7^{\text {th }}\right.$ and $9^{\text {th }}$ place on the scale, respectively), while those ranked as last were aesthetic values.

Similar trends were noted among students of other faculties, who also respected vital values, including fitness and physical condition, while resistance was low on the scale but still higher than aesthetic values, similarly to the results of our study. Students of faculties other than teaching fields attributed the highest importance to moral and religious values $[13,14]$. Similarly, students of the Medical University of Lodz placed vital values, fitness and physical condition, as well as resistance lowest in the rank, and values of truth and moral the highest [14]. The low score of vital values was also found in research among youth aged 16-22 (including students). In both groups of medical volunteers and people not involved in volunteering, vital values scored low, just one position before the last aesthetic values. The respondents declared the highest identification with moral values and values of truth [15]. Vital values also scored low in the system of values declared by Polish teachers. In a group of 580 participants (300 teachers of special education and 280 of other specializations) from Lublin and Subcarpathia, only aesthetic values were classified lower than vital ones, including fitness and physical condition, and resistance. At the same time, moral and sacred religious values scored the highest in the hierarchy [16].

Systematic recreational physical activity, adjusted to the individual capabilities, is an integral element of a healthy lifestyle. Active participation in physical exercises from an early age affects not only a variety of aspects in adult life, but also the quality of life in the elderly age. In order to determine whether future teachers would promote an active lifestyle among their students, the level of teachers' physical activity was identified. It was found that the majority of Polish teaching specialization students $(62.10 \%)$ declared a moderate level of physical activity, with a higher level in 
G. Kosiba, A. Bogacz-Walancik, M. Gacek, A. Wojtowicz, M. Majer, Students' values and physical activity

men than women. The moderate level of physical activity was defined as moderate efforts, i.e. students walked at least 5 times a week for the minimum of 30 minutes a day, while the vigorous level of physical activity comprised students' exercise at least 3 times a week for the minimum of 20 minutes a day, or a combination of efforts (moderate, vigorous, or walking) at least 5 times a week exceeding $600 \mathrm{MET}$-min/week [11]. The total physical activity of the respondents equalled 4819.8 MET-min/week. The trends observed in our study corresponded to the results of research conducted among the youth studying at the State Higher Vocational School in Biała Podlaska [17], which showed that more than half of the students (about 60\%) declared a moderate level of physical activity. Similarly to the teacher education students from Krakow, the respondents from Biała Podlaska most often went walking (959.2 MET$\mathrm{min} /$ week). An intensive level of activity (901.5 MET$\mathrm{min} /$ week) was more frequently reported by men than women $(p<0.05)$. Also, we found that male students were physically active more often than females at an intensive level, but less often at a moderate level. The trend of higher physical activity among men than among women was also observed in other groups, including Polish and Turkish [18], Taiwanese and American [19], and South African [20] college students.

Varying levels of physical activity among college students were reported in research carried out in different countries [21]. A prevalence of anti-health behaviours, including lack of physical activity, among teaching and nursing students (26\%) was identified in research conducted by Irish and French authors [22]. Limited participation in physical activity was also reported among Turkish students of health sciences [23] and South African students [20]; in the latter group, $1 / 3$ declared a low level of physical activity.

A more optimistic tendency in the physical activity among youth, including students, was observed in studies conducted by Polish researchers over the past few years [24-26], including our own findings. For instance, female students of medical faculties from the Gdańsk area mostly declared moderate and high levels of physical activity [24]. Positive trends in physical activity were also reported among male (6227 MET$\mathrm{min} /$ week) and female (5921.5 MET-min/week) students in the United States [19] and Ukraine [27].

Teachers generally indicated a low level of physical activity [28, 29], with the exception of physical education teachers [30].

Taking into consideration that values drive human activity, the relationship between the perception of vital values and the physical activity of students was analysed. It was found that students who respected vital values and the two subscales: fitness and physical condition, as well as resistance to fatigue, also presented a higher level of physical activity. The correlation analysis yielded significant positive correlations between the relevance of vital values, including fitness and physical condition and resistance, and general physical and vigorous activity indicators. It was also shown that as the relevance of vital values, including fitness and physical condition, increased, the moderate level of activity and walking raised as well. At the same time, it was found that the lower the place of vital values, including fitness and physical condition, in the hierarchy of values, the more students tended to spend time sitting.

In general, the following findings were observed: firstly, the level of physical activity increases along with the place of vital values in the hierarchy of values; and secondly, the amount of passive time (seated) is greater as the place of vital values is lower, which confirms the trend that values held by individuals translate into pro-health behaviour, including physical activity.

A positive attitude towards health and its determinants, and the pursuit of pro-health behaviours by future teachers may enhance healthy patterns and the promotion of healthy lifestyle in schoolchildren and the adolescents - potential students later on. School is a proper place to promote healthy physical activity in children and adolescents, and teachers of physical education as well as other specializations should work together to shape positive attitudes towards physical activity in students. They should also serve as models of an active lifestyle and caring for health. On the basis of the results obtained from the study, it can be assumed that pro-health behaviour, and its integral element - physical activity - are slowly paving the way in the lifestyles of different populations, including students - future teachers. However, the perception of health as a precious, desirable value, also in relation to other values, demands a critical analysis of the axiological education of future teachers, so that the position of vital values in the system of values becomes reinforced.

\section{Conclusions}

1. Vital values and their two subscales: fitness and physical condition, as well as resistance, did not score high in the hierarchy of values declared by teacher specialization students, and only preceded the last item - aesthetic values.

2. Future teachers mostly engaged in a moderate level of physical activity, with more men than women 
declaring high and less often moderate levels of physical activity. In addition, male students scored higher on vigorous and moderate activities related to walking, and lower on sitting.

3. Students who rated vital values with the two subscales: fitness and physical condition, as well as resistance, as high, were more likely to undertake physical activity. The strongest relationship was observed between the level of physical activity and the value of fitness and physical condition, while the weakest was between the level of physical activity and the value of resistance in the system of values declared by Krakow students in the field of teaching.

4. Dependences indicating an increase in the level of physical activity along with an increase in the position of vital values among the hierarchy of values and the greater volume of spending one's time passively (in a sitting position) along with decreasing the position of vital values confirm the trend that values held by individuals transfer into pro-health behaviour.

5. With the assumption that the values transfer into pro-health behaviour, special attention should be paid in axiological education of future teachers to the values related to holistically understood health.

\section{Disclosure statement}

No author has any financial interest or received any financial benefit from this research.

\section{Conflict of interest}

The authors state no conflict of interest.

\section{References}

1. Cockerham WC. Medical sociology, $11^{\text {th }}$ ed. Englewood Cliffs: Prentice Hall; 2010.

2. Bailey R, Hillman C, Arent S, Petitpas A. Physical activity: an underestimated investment in human capital? J Phys Act Health. 2013;10(3):289-308; doi: 10.1123/ jpah.10.3.289.

3. Ströhle A. Physical activity, exercise, depression and anxiety disorders. J Neural Transm. 2009;116(6):777784; doi: 10.1007/s00702-008-0092-x.

4. McKenzie TL, Lounsbery MA. Physical education teacher effectiveness in a public health context. Res Q Exerc Sport. 2013;84(4):419-430; doi: 10.1080/02701367. 2013.844025 .

5. Storey KE, Montemurro G, Flynn J, Schwartz M, Wright E, Osler J, et al. Essential conditions for the implementation of comprehensive school health to achieve changes in school culture and improvements in health behaviours of students. BMC Public Health. 2016;16(1): 1133; doi: 10.1186/s12889-016-3787-1.

6. Regulation of the Minister of National Education of 14 February 2017 on the core curriculum for pre-school education and the core curriculum for general education in primary schools, incl. for pupils with moderate and severe intellectual disability, and for general education in stage I sectoral vocational schools, general education in special schools preparing for employment, and general education in post-secondary schools [in Polish]. Journal of Laws of 2017, item 356.

7. Regulation of the Minister of Science and Higher Education of 17 January 2012 on education standards in preparation for work as a teacher [in Polish]. Journal of Laws of 2012, item 131.

8. Recommendations on health promotion and prevention at school [in German]. Bek. des MK vom 8.2.2013-3482113.

9. Decree 97/2015 of March 3, establishing the order and curriculum of primary education in Andalusia [in Spanish].

10. Speller V, Byrne J, Dewhirst S, Almond P, Mohebati L, Norman M, et al. Developing trainee school teachers' expertise as health promoters. Health Educ. 2010;110(6): 490-507; doi: 10.1108/09654281011087288.

11. Biernat E, Stupnicki R, Lebiedziński B, Janczewska L. Assessment of physical activity by applying IPAQ questionnaire. Phys Educ Sport. 2008;52:46-52; doi: 10.2478/ v10030-008-0019-1.

12. Brzozowski P. The Scheler Values Scale: SVS. A manual [in Polish]. Warszawa: PTP; 1995.

13. Wnuk M, Marcinkowski JT, Kalisz Z. Hierarchy of values among students of public health and physiotherapy [in Polish]. Probl Hig Epidemiol. 2010;91(1):169-171.

14. Pawełczyk A, Pawełczyk T, Rabe-Jabłońska J. Medical students hierarchy of values and sense of responsibility. Teach Learn Med. 2012;24(3):211-214; doi: 10.1080/ 10401334.2012.692264.

15. Szulc M, Parchem K. The structure of values and sense of coherence among hospice volunteers [in Polish]. Med Paliat. 2014;6(2):89-94.

16. Parchomiuk M. Value preferences of teachers and their attitudes towards individuals with disabilities. Int $\mathrm{J}$ Disabil Dev Educ. 2015;62(3):276-287; doi: 10.1080/ 1034912X.2015.1020919.

17. Bergier B, Stępień E, Niźnikowska E, Bergier J. Physical activity of male and female students of the State Higher Vocational School in Biała Podlaska, Poland [in Polish]. Med Og Nauk Zdr. 2014;20(2):166-170; doi: 10.5604/ 20834543.1112232.

18. Soguksu K. Physical activity level between Polish and Turkish university students (IPAQ). In: Bergier B (ed.), Physical activity in health and disease. Biała Podlaska: Pope John Paul II State School of Higher Education in Biala Podlaska; 2011; 19-27.

19. Chiang LM, Zhang P, Casebolt K. A comparison of college students' physical activity levels between Taiwan and the United States. Asian J Exerc Sports Sci. 2013;10(2): 49-59.

20. Pengpid S, Peltzer K. Physical inactivity and associated factors among university students in South Africa. Afr J Phys Health Educ Recreat Dance. 2013;19(1):143-153. 


\section{HUMAN MOVEMENT}

G. Kosiba, A. Bogacz-Walancik, M. Gacek, A. Wojtowicz, M. Majer, Students' values and physical activity

21. Bergier J, Bergier B, Tsos A. Variations in physical activity of male and female students from different countries. Iran J Public Health. 2016;45(5):705-707.

22. Deasy C, Coughlan B, Pironom J, Jourdan D, Mcnamara PM. Psychological distress and lifestyle of students: implications for health promotion. Health Promot Int. 2015;30(1):77-87; doi: 10.1093/heapro/dau086.

23. Dayi A, Acikgoz A, Guvendi G, Bayrak L, Ersoy B, Gur C, et al. Determination of factors affecting physical activity status of university students on a health sciences campus. Med Sci Monit. 2017;23:325-334; doi: 10.12659/MSM.899816.

24. Walentukiewicz A, Łysak A, Wilk B. Lifestyle of female medical students [in Polish]. Probl Hig Epidemiol. 2013; 94(2):247-252.

25. Grygiel-Górniak B, Tomczak A, Krulikowska N, Przysławski J, Seraszek-Jaros A, Kaczmarek E. Physical activity, nutritional status, and dietary habits of students of a medical university. Sport Sci Health. 2016; 12(2):261-267; doi: 10.1007/s11332-016-0285-x.

26. Kosiba G, Gacek M, Bogacz-Walancik A, Wojtowicz A. The lifestyle of students - future teachers. Antropomotoryka J Kinesiol Exerc Sci. 2016;74(26):83-94; doi: 10.5604/01.3001.0009.5616.

27. Bergier J, Bergier B, Tsos A. Place of residence as a factor differentiating physical activity in the life style of Ukrainian students. Ann Agric Environ Med. 2016; 23(4):549-552; doi: 10.5604/12321966.1226844.

28. Brito WF, dos Santos CL, do Amaral Marcolongo A, Dias Campos M, Bocalini DS, Antonio EL, et al. Physical activity levels in public school teachers. Rev Saude Publica. 2012;46(1):1-5; doi: 10.1590/S0034-891020 12000100013

29. Woynarowska-Sołdan M, Tabak I. Health enhancing behaviors of teachers and other school staff [in Polish]. Med Pr. 2013;64(5):659-670; doi: 10.13075/mp.5893. 2013.0065.

30. Laudańska-Krzemińska I. Health behaviours and their determinants among physical education and pedagogy students as well as school teachers - a comparison study. Acta Univ Carol Kinanthropol. 2014;50(2):69-78. 